\title{
Letters from the Editors
}

Lucia Szemetová, Jacob Browne \& Anushrut Ramakrishnan Agrwaal

DOI:10.15664/fcj.v19i0.2402

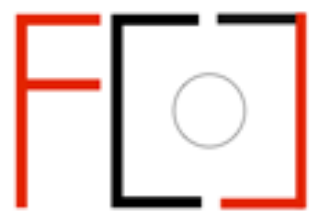

Frames Cinema Journal ISSN 2053-8812

Issue 19 (March 2022)

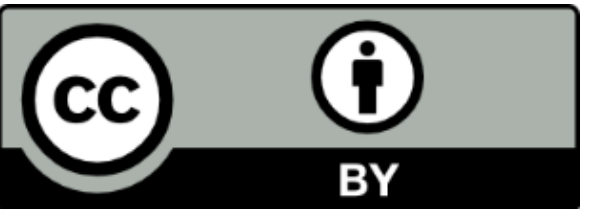


Dear Reader,

Welcome to Issue 19 of Frames Cinema Journal, "Sensing the Archive - Exploring the digital (im)materiality of the moving image archive" guest-edited by Professor Catherine Russell! In recent years, we have all found our movements restricted by the ongoing pandemic. For many researchers, this confinement has been both physical and intellectual, given how travel restrictions have limited the archival visits that were previously our staple. However, the current challenges to archival research also foreground the growing digitisation of historical media and the role of technology in facilitating and structuring research. This issue turns to the tangibility of the medium and the fluidity of the material that arises from mass digitisation. It focuses on digital (im)materiality and the ways in which it produces new instabilities transforming our interactions with audio-visual heritage. The issue examines the sensory properties of archives, dissecting their material vulnerabilities and their relation to cultural histories. The contributions here all address such archival instabilities, challenging the notion of the archive as a neutral space for storage/collection, and reimagine it keeping in mind new sensory modes of historiography. Each piece disrupts the exclusivity of physical access and written documents as the prerequisites for conducting film research and reckons with the various implications of digital transformation and the future of audio-visual heritage.

Our Features Articles examine attempts at historical revision via archival engagement, emphasising filmic materiality and the possibilities of digital media landscape. María A. Vélez-Serna's study of Columbian filmmakers and their remediation of archival images highlights their challenge to historical narratives, while also interrogating the ethical positionalities of those encountering the footage. In thinking about stakeholders, Lola Rémy's article on Sabrina Gschwandtner's film quilts approaches archives as repositories of historical 
and gendered knowledge. Rachel Lallouz's analysis of Barbara Hammer's Nitrate Kisses stresses the importance of tactility in mediating historical traumas and foregrounding lost queer histories. Contemplating such losses, Lennaart van Oldenborgh elucidates the importance of preserving outtakes or unused news footage of historical events in the face of deliberate institutional efforts to shape historical memory. May Chew's discussion of the diasporic archives of home movies of BIPOC immigrants considers the absences inherent in these collections, but also their counter-archival impulses, while Lauren Berliner's discussion of the meaning of "home movies" in today's social media landscape foregrounds the commodification of personal images. Finally, Holly Willis highlights the negotiations made by artists who navigate the personal and algorithmic nature of much contemporary media.

The P.O.V. section offers practitioners' perspective on creative archival practice. Fabiola Hanna \& Irene Lusztig examine the visual translation of the "Letters to the Editor" archive of Ms. Magazine that supplied the basis for Lusztig's performative documentary feature Yours in Sisterhood (2018). Maryam Muliaee reflects on her Recycled Series (2016-2019), which uses a copy machine to produce degenerated images. Questions of preservation and distribution are also asked throughout our Film Featurettes. Guilia Rho's analysis of Barbara Rubin's Christmas on Earth highlights preservation not only of the work, but also of the artist. Claire Henry's article on Sari Brathwaite's [CENSORED] upholds the value of preservation of footage excised under regulatory directives, arguing that Brathwaite's curation of images challenges a gendered history of censorship. Meanwhile, Petra Löffler's study of historical ethnographic films made about indigenous subjects in the Pacific islands emphasises the role of researchers and audiences in activating discourses of decolonisation in the curation of these films. 
Any contemplation of archival interaction and remediation would be incomplete without Video Essays, a form that curates and organises the meaning of historical media. Stephen Broomer's reworking of Joseph Cornell's Rose Hobart alongside footage from Esther Shub and Maya Deren presents the artist's relationship to their self-constructed moving image repositories. Eleni Palis' video essay on archival reuse of Hollywood classics in fiction films comments on the institutional powers that shape cultural and normative histories via the repeated promotion and propagation of images.

Our Book Reviews are also thematically linked to the rest of the issue. We introduce Retrospective Reviews, focusing on an older text to discuss how it has influenced the field, with Glyn Davis' review of Richard Dyer's filmography at the end of Gays and Film, and Anushrut Ramakrishnan Agrwaal's reflection on the new preface to Film Curatorship: Archives, Museums, and the Digital Marketplace. We also offer reviews by Jacob Browne of Justin Remes' Absence in Cinema: The Art of Showing Nothing; by Lucia Szemetová of Jaimie Baron's Reuse, Misuse, Abuse: The Ethics of Audiovisual Appropriation in the Digital Era; and by Wesley Kirkpatrick of Eric Smoodin's Paris in the Dark: Going to the Movies in the City of Light, 1930-1950.

We sincerely thank our guest editor, Catherine Russell, for her generous and deeply insightful contributions to this issue. Her work has been seminal to the field of archival studies, and her influence is reflected throughout this issue. As always, we are extremely grateful for our dedicated editorial team and their tireless efforts. Happy reading!

\section{Lucia Szemetová, Jacob Browne, and Anushrut Ramakrishnan Agrwaal}

*This letter's thumbnail image is an artwork by Sabrina Gschwandtner, Arts and Crafts, 2012. $16 \mathrm{~mm}$ film, polyamide thread, $231 / 2 \times 23$ in. 